\title{
Reflections on the Utility of the Retina as a Biomarker for Alzheimer's Disease: A Literature Review
}

Jennifer Ngolab · Patrick Honma · Robert A. Rissman

\section{ABSTRACT}

As a part of the central nervous system, the retina may reflect both physiologic processes and abnormalities related to diseases of the brain. Indeed, a concerted effort has been put forth to understand how Alzheimer's disease (AD) pathology may manifest in the retina as a means to assess the state of the AD brain. The development and refinement of ophthalmologic techniques for studying the retina in vivo have produced evidence of retinal degeneration in $\mathrm{AD}$ diagnosed patients. In this review, we will discuss retinal imaging techniques implemented to study the changes in AD retina as well as highlight the recent efforts made to correlate such findings to other clinical hallmarks of $\mathrm{AD}$ to assess the viability of the retina as a biomarker for $\mathrm{AD}$.

Keywords: Alzheimer's disease; Fundus camera imaging; Optical coherence tomography; Optical coherence tomography angiography; Retina; Retinal biomarker
Enhanced Digital Features To view enhanced digital features for this article go to: https://doi.org/10.6084/ m9.figshare.10008494.

J. Ngolab · P. Honma · R. A. Rissman ( $₫)$

Department of Neurosciences, University of California, San Diego, CA, USA

e-mail: rrissman@ucsd.edu

P. Honma

Neuroscience Graduate Program, University of California, San Francisco, CA, USA 


\section{Key Summary Points}

Why carry out this study?

Biomarkers of $\mathrm{AD}$ and other neurodegenerative diseases are greatly needed to enhance clinical trials design and recruitment. Presently neuroimaging and CSF biomarkers are expensive and invasive to perform and are considered impractical for large-scale studies. The field has focused on blood-based biomarkers and is now currently working on the identification of proteins in plasma/serum that may reflect neuropathology in brain. The retinal presents a readily accessible tissue for monitoring the brain and could potentially be used in combination with or as a substitute for current AD biomarkers.

Our review focused on currently available data on the retina and AD. We summarize what has been found to date and discuss potential problems and benefits that the data currently generated has yielded.

What was learned from the study?

The human retina may be an important CNS location to detect Alzheimer's pathology.

Data on retinal involvement in $\mathrm{AD}$ and neurodegenerative diseases have been controversial and inconsistent. The reasons behind this may be technical or procedural in nature.

Standardization, round-robin studies and additional scientific meetings are needed to determine how the retinal can be used to denote neurodegenerative disease pathology.

\section{INTRODUCTION}

Alzheimer's disease is a progressive neurodegenerative disease that is characterized by memory loss and cognitive deficits in elderly adults, usually $>65$ years of age. Post-mortem analysis of the brain for amyloid-beta $(A \beta)$ plaques and neurofibrillary tangles (NFT) comprised of the microtubule protein tau remains the gold standard for AD diagnosis $[1,2]$. There is sufficient evidence to suggest that abnormal $\mathrm{A} \beta$ expression and tau precede cognitive deficits, resulting in the addition of biomarkers to the $\mathrm{AD}$ clinical guidelines set forth by the National Institute of Aging/Alzheimer Association (NIA/AA) [3]. Currently, AD biomarkers are quantified through positron emission tomography (PET) or concentration in cerebral spinal fluid (CSF). While these biomarkers provide information regarding $A \beta$ plaque load and neurodegeneration, such tests are invasive and expensive. Additional biomarkers that are noninvasive and inexpensive would only serve to support an early diagnosis of AD.

Cognitive visual changes manifest in patients in the early stages of $\mathrm{AD}$, including difficulty reading and finding objects [4, 5], depth perception, perceiving structure from motion [4-6], color recognition [4, 7] and impairment of spatial contrast sensitivity $[7,8]$. Previously, these defects were thought to be due to pathologic changes in the cortex. Analysis of post-mortem retinal tissue identified retinal ganglion cell loss and optic nerve head thinning in $\mathrm{AD}$ patients $[9,10]$. The retina is thought of as a "window to the brain" as it stems from the same embryonic precursor as the central nervous system (CNS) and exhibits similar characteristics to the brain $[11,12]$. Changes in neuronal and vascular structures in the retina as determined by in vivo clinical measures are evident in multiple neurologic diseases, highlighting the retina as a potential biomarker for the CNS [13].

Studies in transgenic mice heavily suggest that the abundant expression of $A \beta$ and tau results in neurodegeneration and visual loss. $A \beta$ accumulates within cell bodies and along the microvasculature in transgenic mouse models of $\mathrm{AD}$ 10-15 and Octodon degus, a natural model of sporadic AD [14]. Retinal A $\beta$ plaques appear at 2.5 months of age in $\mathrm{APP}(\mathrm{SWE}) /$ PS1( $\Delta$ E9) mice, 2-3 months before plaques form in the brain [15]. These animal models also demonstrated a significant reduction in visual function and visuospatial recognition 
compared with healthy controls [16-18], mirroring deficits reported in $\mathrm{AD}$ patients. $\mathrm{A} \beta$ was shown to exert its neurotoxic effect in the retina by upregulating the expression of an inflammatory cytokine (MCP-1), a microglial (F4/80) and apoptotic marker in the ganglion cell layer [19], consequently inducing microglia infiltration and astrogliosis in the retina $[20,21]$. As a result, retinal ganglion cell dendritic atrophy precedes cell loss, inner retinal thinning, reduction of axonal density in the optic nerve and reduced scotopic threshold response amplitudes measured through electroretinogram $[16,22,23]$. While the studies in mouse models simulate symptoms observed in $\mathrm{AD}$ patients and suggest a potential mechanism for the visual alterations observed in humans, it is unclear if similar processes occur in the human retina, as disease progression between species may utilize different pathways and therefore bias results.

This review will discuss the multiple retinal imaging methods used to evaluate the human retina in $\mathrm{AD}$ patients. We will discuss significant findings as well as outstanding issues with the currently used retinal imaging techniques. Also, we will reflect on how alterations of the retina corroborate with other biomarkers of $\mathrm{AD}$, such as protein load in the brain as well as CSF. This article is based on previously conducted studies and does not contain any studies with human participants or animals performed by any of the authors.

\section{METHODS}

We performed a literature search in PubMed and Web of Science for studies published before June 2019. Keywords included "Alzheimer's disease," "retina" and "imaging." A total of 112 articles were identified. Studies in our review investigated changes in the retina between Alzheimer's disease diagnosed patients and healthy controls, through the retinal thickness, vascular alterations or in vivo inclusion detection. Studies conducted in mice as well as repeats were discarded. The identification of subsequent articles occurred throughout the literature review process. Our review discusses previously conducted studies and does not contain any studies with human participants or animals performed by any of the authors.

\section{RETINAL THICKNESS}

Numerous studies into AD-mediated retinal changes evaluated the thinning of the retinal nerve fiber layer, as histopathologic analysis of postmortem ocular tissue from $\mathrm{AD}$ patients identified optic nerve degeneration and retinal ganglion cell (RGC) loss compared with controls $[9,10]$. Non-invasive retinal imaging technology such as optical coherence tomography (OCT) uses low-coherence interferometry to produce high-resolution cross-sectional scans of the retinal architecture [24]. While other ocular techniques reported similar findings [25-28], OCT produced data with higher diagnostic value compared with semiquantitative methods such as red-free photography [29], and the reliability and reproducibility of OCT retinal scans have been assessed in normal and cognitively impaired individuals [30, 31]. Thinning of the peripapillary retinal nerve fiber layer (pRNFL), the retinal layer around the optic nerve head, is associated with other retinopathies and neurodegenerative diseases [32]. The pRNFL around the optic head is segmented into four quadrants: superior, inferior, nasal and temporal. Previous meta-analyses have concluded that retinal thinning, particularly around the pRNFL, may be a reliable indicator of neurodegeneration in AD patients [33-37]. Thinning of the pRNFL was apparent in the inferior [38-48] or superior peripapillary quadrant in AD patient retinas [26, 40-43, 45-56]. Meta-analysis of studies performed on patients diagnosed with mild cognitive impairment (MCI) suggest retinal thinning may also occur but to a lesser extent than in AD-diagnosed patients [33, 35, 36]. Kesler and colleagues found significant inferior quadrant pRNFL thinning in MCI-diagnosed patients, while the superior and inferior quadrants were thinner in $\mathrm{AD}$ patients, suggesting a potential retinal diagnostic index to differentiate between MCI and $\mathrm{AD}$ [44]. However, subsequent studies in MCI patients report thinning in the temporal 
[46] and nasal quadrant [53]. Thinning of the pRNFL may be an indication of cognitive impairment associated with $\mathrm{AD}$, yet signs indicative of early disease progression remains inconclusive.

The macula may also be a potential AD biomarker because of the high density of RGCs around the fovea [57]. Histopathologic studies quantified as much as 25\% RGC loss within the macula in post-mortem AD retinal tissue [58]. Retinal cells are organized in layers within the retina to optimize the processing of visual stimuli, with RGCs contained within the ganglion cell-inner plexiform layer (GC-IPL). Recent OCT studies indicate that the macular GC-IPL is reduced in AD patients compared with age-matched controls [33, 43, 53, 59, 60]. These data support the observation of fewer RGCs in the AD retina, further implicating retinal neurodegeneration in $\mathrm{AD}$. As seen in the pRNFL, decreased macular retinal thickness is less prevalent in MCI patients. Further assessment of macular thickness may provide additional insight into RGC degeneration in AD.

While evidence for the association of pRNFL thinning and late stage $\mathrm{AD}$ is prevalent, recent studies contradict previous findings when assessing retinal thickness in the earlier stages of $\mathrm{AD}$ progression [61-66]. A majority of these studies were performed on a spectral-domain OCT (SD-OCT) machine, a newer generation of OCT technology that improved scan time and resolution over the previous time-domain OCT (TD-OCT) machines [67]. As noted by den Haan and colleagues in 2017, there are discrepancies between previous generations of OCT, as studies using TD-OCT machines reported greater differences in pRNFL thickness between $A D$ and healthy controls [35]. While OCT studies highlight changes observed in AD patients, similar degeneration occurs in other retinopathies. Current imaging modalities cannot distinguish retinal changes caused by glaucoma or dementia, as a recent study using SD-OCT failed to report significant differences in pRNFL thinning between $\mathrm{AD}$ and preperimetric glaucoma patients [68]. Although SD-OCT improved resolution may eventually identify features unique to $\mathrm{AD}$, a diagnosis using OCT alone is not sufficient.

\section{RETINAL VASCULAR CHANGES IN AD}

Vascular diseases are a risk factor of dementia, and evidence suggests AD pathophysiology includes a vascular component [69, 70]. For example, abnormally reduced cranial blood flow is observed in AD patients through transcranial Doppler analysis [71]. Disruptions in the cerebral vasculature, such as infarcts and hemorrhages, are also documented in AD postmortem tissue [69]. The brain and retina share anatomical and physiologic similarities, and alterations in the retinal microvasculature may emulate changes in the brain [72]. Disruptions of the retinal vasculature are reported in cognitively impaired individuals [72]. Abnormal retinal blood flow has also been measured in $\mathrm{AD}$, implicating the retinal vasculature as another potential AD retinal biomarker [50]. While other techniques exist, two primary ocular imaging modalities used to study AD-related vascular structural changes are retinal fundus imaging and OCT angiography (OCTA).

Retinal fundus imaging is a standardized technique that allows for the quick assessment of the retinal vasculature [73]. Semiautomated analysis of retinal photographs provides quantification of prominent vasculature changes associated with blood pressure such as inner vessel width (caliber), tortuosity and global branch patterning (fractal dimension) [74]. Retinal vasculature assessment from two population-based cohorts identified changes in vessel caliber were associated with dementia in hypertensive individuals [75] and individuals diagnosed vascular dementia but not $\mathrm{AD}$ [76]. Various alterations in the retinal vasculature were observed in individuals diagnosed with AD compared with control [77]. However, an independent study reported significant differences in retinal fraction in individuals diagnosed with vascular impairment but not early stage AD [78]. The APOE $\varepsilon 4$ allele is associated with small vessel disease and a genetic risk factor for $\operatorname{AD}[79,80]$. Vessel structure and composition measured through retinal vessel central reflex were significantly associated with $A P O E \& 4$ status [77]. The association between vessel central reflex and $\mathrm{AD}$ was not significant when $A P O E \& 4$ status was taken 
into account. Collectively, these data suggest that vascular retinal measurements could be a reliable indication of vascular infarctions often comorbid with $\mathrm{AD}$. Meta-analysis of retinal fundus imaging studies concluded retinal fractal dimensions were consistently altered in AD patients, suggesting measuring vascular complexity may be a viable biomarker when using retinal fundus imaging [81-83].

The retinal vasculature is organized into distinct networks within the retinal layers, and each vascular network comprises a unique set of microvessels [84]. As cerebral microvasculature distortions in $\mathrm{AD}$ brains lead to disrupted blood flow, the retinal microvasculature may reflect similar malformations. Retinal fundus imaging lacks the resolution to discern between the superficial and deep capillary networks [85]. Advances in OCT technology have allowed for the detailed analysis of the retinal vascular networks through OCTA [86]. The movement of objects, such as red blood cell flow, creates variations in the OCT signal, making it an ideal contrast agent for vascular imaging. Repeated scans are analyzed in OCTA to subtract regions of static OCT signal and highlight regions of varying OCT signal, producing an in-depth visualization of the retinal microvasculature.

Several groups demonstrated retinal vessel density reduction of the superficial capillary plexus (SCP), the vascular network within the GC-IPL, in AD-diagnosed patients [87-91]. Jiang and colleagues noted a marginal decrease in GC-IPL thickness in AD compared with MCI and healthy controls [88]. Reduced GC-IPL thickness was correlated with the deep capillary plexus (DCP), a vascular network located in the inner retina mainly composed of capillaries [88]. Because capillary dysfunction is associated with AD-mediated neurodegeneration, it is possible that the DCP dysfunction is highly susceptible in the $\mathrm{AD}$ retina and may indicate disease progression [92]. Retinal microvessel density of the DCP was also significantly lower in $\mathrm{AD}$ and $\mathrm{MCI}$ patients from the same study [88]. However, subsequent OCTA analyses did not observe DCP vessel density reduction in MCI $[91,93]$ or $\mathrm{AD}[87,93]$. Additional analysis of the SCP and DCP through OCTA may provide more information about the specific vascular networks altered in $\mathrm{AD}$ and MCI.
The fovea avascular zone (FAZ) is a specialized region of the fovea that lacks retinal blood vessels in order to reduce light scattering [94]. The FAZ can indicate disease progression, as the width and circumference of the FAZ correlate with capillary nonperfusion [95]. A few studies utilizing OCTA observed larger FAZ in $\mathrm{AD}[89,90]$. While increased areas of FAZ were reported in one study that had screened their population with $\mathrm{AD}$ biomarkers [96], other groups failed to observe similar changes in their preclinical AD cohort $[91,97]$. One possible explanation for the positive result could be the variation in $\mathrm{AD}$ biomarkers used to identify experimental subjects. An alternative explanation may be that increased FAZ may be indicative of later stages of $\mathrm{AD}$.

As oxygen metabolism is likely perturbed in $\mathrm{AD}$ [98], another possible retinal vascular measurement is oxygen consumption using retinal oximetry [99]. Hemoglobin saturated with oxygen is sensitive to wavelengths at $600 \mathrm{~nm}$ but not $570 \mathrm{~nm}$. Optical densities are calculated in the retinal vessels to measure relative vessel oxygenation [100]. The first study to analyze AD retinas with retinal oximetry detected elevated venous oxygen saturation in $\mathrm{AD}$ patients compared with control individuals, suggesting that less oxygen is leaving the blood [101]. Similar results were observed in patients diagnosed with MCI, hinting that faulty oxygen metabolism occurs early on in AD [102]. Decreased venous blood flow was also seen in MCI patients as well as $\mathrm{AD}$ patients, possibly contributing to the disruption of retinal oxygen consumption $[50,90]$. In summary, these results suggest that the retinal vasculature is impaired in such a way to ultimately reduce blood flow. One vascular measure may not suffice as a definitive sign of $\mathrm{AD}$; however, quantifying a few key measures such as oxygen saturation and retinal vessel density may contribute to developing a distinct profile of $\mathrm{AD}$ progression in the retina.

\section{DETECTING AD PATHOLOGY IN THE RETINA}

Retinal neural fiber layer degeneration and retinal vasculature configuration are also characteristic of other retinopathies independent of 
AD [103-105]. The possibility of detecting the classic $\mathrm{AD}$ hallmarks such as fibrillar $\mathrm{A} \beta$ plaques or NFTs in the retina alongside other retinal changes could further support an AD diagnosis. However, $A \beta$ and tau are also implicated in other age-related retinopathies. Inclusions that resemble the extracellular inclusions called drusen associated with early stage age-related macular degeneration (AMD) [106] were detected in the retinal periphery of $\mathrm{AD}$ patients through ultra-widefield fundus imaging [107]. Several studies report the presence of $A \beta$ within the retinal pigmented epithelium (RPE) cells and drusen in AMD patients [108-110]. Reduction of the outer retina such as the photoreceptor layer is associated with early AMD progression [111-113]. One study failed to detect differences in any of the outer retinal layers among $\mathrm{MCI}, \mathrm{AD}$ and healthy controls, implying that photoreceptor layer thinning is unique to early AMD [114]. Loss of RGCs is observed in both glaucoma and $\mathrm{AD}$, implying a relationship between the two diseases [115]. In animal models of glaucoma, apoptosis of RGCs is associated with increased production of amyloid [116], and inhibiting aggregation may prevent RGC loss [117]. Tau-mediated pathogenic mechanisms may be involved in retinal degeneration, as suggested by decreased tau levels in the retina [118] and increased levels of tau in the vitreous body of patients with glaucoma and diabetic retinopathy [119]. Elevated intraocular pressure (IOP) present in glaucoma may play a role in tau phosphorylation [118]. However, no differences in IOP were detected in $\mathrm{AD}$ patients compared with controls [51, 120]. It is possible that although $A \beta$ and tau may be present in glaucoma and AMD, key differences may be sufficient to distinguish the different forms of retinopathy from AD.

The work from the Koronyo-Hamaoui laboratory has provided evidence for detecting retinal $A \beta$ detection in vivo. $A$ pilot study administering curcumin, a turmeric-derived fluorophore known to bind to $A \beta$ plaques [121], to $\mathrm{AD}$ and $\mathrm{AMD}$ patients reported abundant curcumin-positive objects in the peripheral retina of $\mathrm{AD}$ and $\mathrm{AMD}$ patients [15]. Histologic analysis of postmortem retinas performed by the same group detected $A \beta$-positive inclusions using curcumin and a panel of $A \beta$-specific antibodies in $\mathrm{AD}$ diagnosed patients compared with controls $[15,52,122]$. Of note, they showed that $A \beta$-positive inclusions were more frequently found in the periphery of the superior quadrant and were uncommon in the macula. Diverse $A \beta$ deposits often associated with blood vessels were found predominantly in the ganglion cell layer [122]. In contrast, other groups have been unsuccessful in detecting retinal $A \beta$ deposition in $A D$ patients. Williams et al. were unable to detect any $A \beta$, tau inclusion or deposits in the retinas of $17 \mathrm{AD}$-related cases [123]. Schön and collaborators did not find fibrillary accumulations of $A \beta$ in six postmortem AD retinas [124]. Similarly, Ho et al. examined eyes from $11 \mathrm{AD}$ cases and 6 agematched controls and did not observe amyloid deposits in the lens, retina or other ocular structures in AD eyes [125]. Hinton and colleagues also failed to find amyloid in the retinas of four AD patients [126], and Leger et al. did not find intraretinal amyloid in eyes of older patients or two AD patients [127]. Lastly, Jiang et al. completed a meta-analysis of five of the aforementioned studies and found significant statistical heterogeneity between their results, which was thought to be due to the fact that the first study by Koronyo-Hamaoui and coworkers used five antibody clones in contrast to the other four studies, which used only one clone [128]. The authors concluded that this metaanalysis did not provide sufficient evidence to suggest whether pathologic accumulation of retinal $A \beta$ could be used as a diagnostic tool for $\mathrm{AD}$. The inability to reproduce $\mathrm{A} \beta$ human retinal staining can be attributed to technical inconsistencies such as the tissue preparation or immunohistochemical protocol [129]. Our laboratory has performed immunohistochemical analysis on post-mortem $\mathrm{AD}$ and control retinal tissue and observed diffuse $A \beta$ staining. While promising, we would like to refine our technique. More importantly, the variation in $A \beta$ staining as well as the other retinal markers discussed above may lie in the heterogeneity of the sample population.

Detection of retinal tau is promising as it is known to play a pivotal role in retinopathy progression by interacting with axonal 
transport signaling pathways and bridging various signaling protein complexes [130]. AT8positive detecting phosphorylated tau inclusions were observed in post-mortem retinal tissue from six $A D$ cases as well as retinal tissue from two progressive severe palsy cases [124]. Using several antibodies to characterize the presence of $A \beta$ and tau in post-mortem brain and retina, den Haan and colleagues detected phosphorylated tau in the inner and outer plexiform layers of retinal tissues from $\mathrm{AD}$ cases and $\mathrm{A} \beta$ signal in both $\mathrm{AD}$ and control cases [131]. Additionally, phosphorylated tau but not $\mathrm{A} \beta$ staining was present in both brain and retinal tissue of AD cases. Two cognitively normal cases also exhibited retinal phosphorylated tau staining. To summarize, retinal tau may indicate tauopathy in the brain, but interpretations may also be complicated by retinal diseases such as glaucoma.

Fluorescent live imaging ophthalmoscopy (FLIO) is an emerging technology that measures the autofluorescence of the retinal fluorophores, calculating the overall fluorescent lifetime of a fluorophore. The fluorescent lifetime, or the time elapsed from peak excitation of the fluorophore to ground state, can be used to detect abnormalities in the retina. A couple of FLIO studies observed a significant correlation between $\mathrm{AD}$ diagnosis as well as AD CSF biomarker concentrations with fluorescence lifetime [132, 133]. Fluorescence lifetime measurements also correlated with GC-IPL thickness measured through OCT as well as with $\mathrm{A} \beta$ and tau CSF levels [132]. While additional studies are needed to further validate these finding, the use of FLIO in AD retinal diagnosis is promising.

\section{USING RETINAL ALTERATIONS IN CONJUNCTION WITH ESTABLISHED AD BIOMARKERS}

Age is a risk factor of $\mathrm{AD}$ and other retinopathies that may confound the use of the retina as a biomarker for $\mathrm{AD}$. The retinal nerve fiber layer naturally decreases with age at a rate of $0.44 \mu \mathrm{m}$ per year [134]. A thinner GC-IPL and retinal nerve fiber layer was detected in individuals $\geq$ 50 years [135-137]. Retinal layer thickening is observed in the outer retina of older individuals, possibly because of decreased activity of the RPE $[135,138,139]$. While studies include an agematched healthy control group to account for these issues, it is difficult to conclude with high confidence whether changes in the retina are inflicted by $\mathrm{AD}$ pathology or a result of the normal aging process. Longitudinal studies would provide information about retinal thickness and disease progression over time to account for these potential cofounders.

Early longitudinal studies have focused on assessing retinal thickness in elderly cohorts to assess the relationship of retinal degeneration and disease progression. In a 25-month study following a cohort of nondemented elderly individuals, significant thinning in the inferior pRNFL quadrant was observed in individuals whose cognitive abilities had declined [38]. Reduction of the pRNFL was observed after 12 months in patients diagnosed with mild to moderate AD [41]. Drusen-like inclusions in the peripheral retina increased over a 2-year period in clinically diagnosed $\mathrm{AD}$ patients, suggesting the continued development of retinal inclusions may occur late in the disease [107]. Recent studies have utilized other biomarkers such as functional imaging and CSF $\mathrm{A} \beta$ and tau concentrations to further understand the relevance of retinal thinning to $\mathrm{AD}$ progression. After individuals were sorted into preclinical $A D$ or control groups based on A $\beta$ PET imaging, Santos et al. reported a decrease in retinal layer thickness in the preclinical group as well as an inverse relationship between retinal layer thickness and $A \beta$ accumulation in the preclinical AD group [140]. In another study, elderly individuals determined to be cognitively normal at the beginning of the study were assessed by magnetic resonance imaging and OCT to correlate retinal thickness to cingular cortical thickness. Decreased retinal thickness in the inferior peripapillary quadrant was associated with cortical atrophy as well as episodic memory 12 months after initial examination [39]. In summary, longitudinal studies have provided 
support for using the retina as a feasible biomarker for the early diagnosis of AD.

However, other studies implementing $A \beta$ PET [97], CSF [87] or both AD biomarkers [141] failed to repeat retinal changes observed in clinically diagnosed AD populations. Although alterations in macular vessel density were observed in the biomarker-positive group, Lahme and colleagues concluded that they were not due to AD pathology, but vascular diseases comorbid with $\mathrm{AD}$ [87]. In a comprehensive study using multiple ophthalmologic techniques to quantify various retinal vasculature parameters, no significant vascular changes were reported between $\mathrm{AD}$ biomarker-positive and -negative groups [141]. A similar study conducted between $A \beta$-positive patients converted to $A D$ and $A \beta$-negative patients diagnosed with vascular cortical impairment found a reduced fractal dimension in the $A \beta$-negative group diagnosed with vascular impairment [78]. Furthermore, retinal thinning and parietal cortical atrophy were observed in both $A \beta$-positive and -negative individuals, leading the authors to conclude thinning of the retina correlates with the parietal lobe independent of the presence of $A \beta$ [60]. These observations suggest that the alterations in the retina are not directly due to $A \beta$ accumulation but through other mechanisms that are comorbid with $\mathrm{AD}$.

Prognostic studies using AD biomarkers have provided new insight into retinal changes in the preclinical stages of $\mathrm{AD}$. Asymptomatic individuals with high levels of $A \beta$-PET signal exhibit higher retinal vessel densities as well as larger vascular widths [97, 142], suggesting higher blood flow in the retina with $A \beta$ accumulation. Increased retinal blood flow can be induced by hypoxia, increasing the vascular density observed in OCTA [143]. A recent study tracking retinal vessel dynamics identified vasculature impairment in MCI-diagnosed patients. Further analysis correlated arteriole dilation with CSF $A \beta$ levels, with the authors proposing $A \beta$ levels in brain and retina may impede retinal vascular function [93]. Taken together, these results support the hypothesis that inflammation instigated by $A \beta$ accumulation induces the retina to go into a hypoxic state similar to the brain [144]. Activated microglia were detected in the retinas of pre-symptomatic triple-transgenic mice, implicating that $A \beta$ plaques and NFTs can induce gliosis in the retina [145]. In a case-controlled cross-sectional study, retinal thickening was revealed in MCI patients through multivariate regression analysis [66]. The authors speculate that retinal thickness temporarily increases as an inflammatory response in the early stages of $\mathrm{AD}[66,146]$. The dynamic state of the retina due to gliosis may partially explain the varied results previously reported in the prodromal population.

Larger prospective longitudinal studies may provide a more comprehensive assessment of the utility of ocular markers to diagnose AD. Retinal imaging studies can be added on to existing larger studies. One such example of this is the A4/LEARN clinical trial, an ongoing study that has enrolled over 1500 asymptomatic individuals screened through PET for elevated $\mathrm{A} \beta$ levels. Added onto the study is a retinal imaging component that has two objectives: (1) determine the incidence of $A \beta$ accumulation in retina relative to brain $\mathrm{AD}$ pathology and (2) correlate retinal $A \beta$ and $A \beta$ brain PET to cognitive measures across both arms. All participants in the retinal imaging add on are administered curcumin and scanned by fundus camera for curcumin-positive inclusions. After the completion of the double-blind portion of the study, participants of the A4 trial will be offered the opportunity to continue treatment on the open-label extension. The open-label extension will provide valuable information with regard to delayed start analysis. Amendments to studies such as the one described above will provide further data to determine if the retina is a reliable biomarker for early $\mathrm{AD}$ diagnosis.

\section{CONCLUSION}

The retina may serve as a "window into the brain" that may potentially provide a non-invasive and simple method to diagnose AD. Studies have highlighted distinct changes in the ocular and vascular structure in $\mathrm{AD}$ patients as well as uncovered distinct retinal changes in early stages of $\mathrm{AD}$ indicative of inflammation. However, several inconsistencies are reported 
questioning the utility of the retina as a reliable biomarker for diagnosing AD. While small sample sizes may be influencing results, another concern is the variation in techniques used to measure the retina. Although technology may provide higher resolution and ease of data acquisition, one also needs to remember that such techniques should be reproducible and also scalable to previous iterations. Furthermore, other factors such as retinopathy and aging similarly alter the retina, confounding the retinal alterations possibly due to AD. Future studies should consider measuring the retinal vasculature, retinal fiber layer as well as potential $\mathrm{A} \beta$ retinal inclusions to compare disease progression, ideally in individuals pre-screened through other biomarkers.

\section{ACKNOWLEDGEMENTS}

Funding. No funding or sponsorship was received for this study or publication of this article.

Authorship. All named authors meet the International Committee of Medical Journal Editors (ICMJE) criteria for authorship for this article, take responsibility for the integrity of the work as a whole, and have given their approval for this version to be published.

Disclosures. Jennifer Ngolab, Robert A. Rissman and Patrick Honma have nothing to disclose.

Compliance with Ethics Guidelines. This article is based on previously conducted studies and does not contain any studies with human participants or animals performed by any of the authors.

Open Access. This article is distributed under the terms of the Creative Commons Attribution-NonCommercial 4.0 International License (http://creativecommons.org/licenses/ by-nc/4.0/), which permits any noncommercial use, distribution, and reproduction in any medium, provided you give appropriate credit to the original author(s) and the source, provide a link to the Creative Commons license, and indicate if changes were made.

\section{REFERENCES}

1. Roher AE, Kokjohn TA, Clarke SG, Sierks MR, Maarouf CL, Serrano GE, et al. APP/A $\beta$ structural diversity and Alzheimer's disease pathogenesis. Neurochem Int. 2017;110:1-13.

2. Aisen PS, Cummings J, Jack CR, Morris JC, Sperling R, Frölich L, et al. On the path to 2025: understanding the Alzheimer's disease continuum. Alzheimers Res Ther [Internet]. 2017. https://doi.org/ 10.1186/s13195-017-0283-5.

3. Jack CR, Albert MS, Knopman DS, McKhann GM, Sperling RA, Carrillo MC, et al. Introduction to the recommendations from the National Institute on Aging-Alzheimer's Association workgroups on diagnostic guidelines for Alzheimer's disease. Alzheimers Dement. 2011;7:257-62.

4. Katz B, Rimmer S, Iragui V, Katzman R. Abnormal pattern electroretinogram in Alzheimer's disease: evidence for retinal ganglion cell degeneration? Ann Neurol. 1989;26:221-5.

5. Lee AG, Martin CO. Neuro-ophthalmic findings in the visual variant of Alzheimer's disease. Ophthalmology. 2004;111:376-80.

6. Mendez MF, Cherrier MM, Meadows RS. Depth perception in Alzheimer's disease. Percept Mot Skills. 1996;83:987-95.

7. Cronin-Golomb A. Vision in Alzheimer's disease. Gerontologist. 1995;35:370-6.

8. Gilmore GC, Whitehouse PJ. Contrast sensitivity in Alzheimer's disease: a 1-year longitudinal analysis. Optom Vis Sci. 1995;72:83-91.

9. Blanks JC, Hinton DR, Sadun AA, Miller CA. Retinal ganglion cell degeneration in Alzheimer's disease. Brain Res. 1989;501:364-72.

10. Sadun AA, Bassi CJ. Optic nerve damage in Alzheimer's disease. Ophthalmology. 1990;97:9-17.

11. Sinn R, Wittbrodt J. An eye on eye development. Neural Develop. 2013;130:347-58.

12. London A, Benhar I, Schwartz M. The retina as a window to the brain-from eye research to CNS disorders. Nat Rev Neurol. 2013;9:44-53. 
13. Nguyen CTO, Hui F, Charng J, Velaedan S, van Koeverden AK, Lim JKH, et al. Retinal biomarkers provide "insight" into cortical pharmacology and disease. Pharmacol Ther. 2017;175:151-77.

14. Du LY, Chang LYL, Ardiles AO, Tapia-Rojas C, Araya $\mathrm{J}$, Inestrosa $\mathrm{NC}$, et al. Alzheimer's disease-related protein expression in the retina of octodon degus. PLOS One. 2015;10:e0135499.

15. Koronyo-Hamaoui M, Koronyo Y, Ljubimov AV, Miller CA, Ko MK, Black KL, et al. Identification of amyloid plaques in retinas from Alzheimer's patients and noninvasive in vivo optical imaging of retinal plaques in a mouse model. NeuroImage. 2011;54:S204-17.

16. Perez SE, Lumayag S, Kovacs B, Mufson EJ, Xu S. $\beta$ amyloid deposition and functional impairment in the retina of the APPswe/PS1 $\Delta \mathrm{E} 9$ transgenic mouse model of Alzheimer's disease. Investig Opthalmol Vis Sci. 2009;50:793.

17. Le Cudennec C, Faure A, Ly M, Delatour B. One-year longitudinal evaluation of sensorimotor functions in APP751SL transgenic mice. Genes Brain Behav. 2008;7:83-91.

18. Hale G, Good M. Impaired visuospatial recognition memory but normal object novelty detection and relative familiarity judgments in adult mice expressing the APPswe Alzheimer's disease mutation. Behav Neurosci. 2005;119:884-91.

19. Ning A, Cui J, To E, Ashe KH, Matsubara J. Amyloid$\beta$ deposits lead to retinal degeneration in a mouse model of Alzheimer disease. Investig Opthalmol Vis Sci. 2008;49:5136.

20. Edwards MM, Rodríguez JJ, Gutierrez-Lanza R, Yates J, Verkhratsky A, Lutty GA. Retinal macroglia changes in a triple transgenic mouse model of Alzheimer's disease. Exp Eye Res. 2014;127:252-60.

21. Liu B, Rasool S, Yang Z, Glabe CG, Schreiber SS, Ge $\mathrm{J}$, et al. Amyloid-peptide vaccinations reduce $\beta$ amyloid plaques but exacerbate vascular deposition and inflammation in the retina of Alzheimer's transgenic mice. Am J Pathol. 2009;175:2099-110.

22. Williams PA, Thirgood RA, Oliphant H, Frizzati A, Littlewood E, Votruba M, et al. Retinal ganglion cell dendritic degeneration in a mouse model of Alzheimer's disease. Neurobiol Aging. 2013;34: 1799-806.

23. Gupta VK, Chitranshi N, Gupta VB, Golzan M, Dheer Y, Wall RV, et al. Amyloid $\beta$ accumulation and inner retinal degenerative changes in Alzheimer's disease transgenic mouse. Neurosci Lett. 2016;623:52-6.
24. Huang D, Swanson EA, Lin CP, Schuman JS, Stinson WG, Chang W, et al. Optical coherence tomography. Science. 1991;254:1178-81.

25. Kergoat H, Kergoat M-J, Justino L, Chertkow H, Robillard A, Bergman H. An evaluation of the retinal nerve fiber layer thickness by scanning laser polarimetry in individuals with dementia of the Alzheimer type. Acta Ophthalmol Scand. 2001;79: 187-91.

26. Hedges TR, Galves RP, Speigelman D, Barbas NR, Peli E, Yardley CJ. Retinal nerve fiber layer abnormalities in Alzheimer's disease. Acta Ophthalmol Scand. 2009;74:271-5.

27. Tsai CS, Ritch R, Schwartz B, Lee SS, Miller NR, Chi $\mathrm{T}$, et al. Optic nerve head and nerve fiber layer in Alzheimer's disease. Arch Ophthalmol Chic Ill. 1960;1991(109):199-204.

28. Tuulonen A, Lehtola J, Airaksinen PJ. Nerve fiber layer defects with normal visual fields. Do normal optic disc and normal visual field indicate absence of glaucomatous abnormality? Ophthalmology. 1993;100:587-97 (discussion 597-598).

29. Soliman MAE, Van Den Berg TJTP, Ismaeil AAA, De Jong LAMS, De Smet MD. Retinal nerve fiber layer analysis: relationship between optical coherence tomography and red-free photography. Am J Ophthalmol. 2002;133:187-95.

30. Loh EHT, Ong Y-T, Venketasubramanian N, Hilal S, Thet N, Wong TY, et al. Repeatability and reproducibility of retinal neuronal and axonal measures on spectral-domain optical coherence tomography in patients with cognitive impairment. Front Neurol [Internet]. 2017. https://doi.org/10.3389/fneur. 2017.00359.

31. Polo V, Garcia-Martin E, Bambo MP, Pinilla J, Larrosa JM, Satue M, et al. Reliability and validity of Cirrus and Spectralis optical coherence tomography for detecting retinal atrophy in Alzheimer's disease. Eye. 2014;28:680-90.

32. Jindahra P, Hedges TR, Mendoza-Santiesteban CE, Plant GT. Optical coherence tomography of the retina: applications in neurology. Curr Opin Neurol [Internet]. 2010;23. https://journals.lww.com/coneurology/Fulltext/2010/02000/Optical_ coherence_tomography_of_the_retina_.5.aspx.

33. Chan VTT, Sun Z, Tang S, Chen LJ, Wong A, Tham CC, et al. Spectral-domain OCT measurements in Alzheimer's disease. Ophthalmology. 2019;126: 497-510.

34. Thomson KL, Yeo JM, Waddell B, Cameron JR, Pal S. A systematic review and meta-analysis of retinal nerve fiber layer change in dementia, using optical 
coherence tomography. Alzheimers Dement Diagn Assess Dis Monit. 2015;1:136-43.

35. den Haan J, Verbraak FD, Visser PJ, Bouwman FH. Retinal thickness in Alzheimer's disease: a systematic review and meta-analysis. Alzheimers Dement Amst Neth. 2017;6:162-70.

36. Coppola G, Di Renzo A, Ziccardi L, Martelli F, Fadda A, Manni G, et al. Optical coherence tomography in Alzheimer's disease: a meta-analysis. PLoS One. 2015;10:e0134750.

37. He X-F, Liu Y-T, Peng C, Zhang F, Zhuang S, Zhang J-S. Optical coherence tomography assessed retinal nerve fiber layer thickness in patients with Alzheimer's disease: a meta-analysis. Int J Ophthalmol. 2012;5:401-5.

38. Shi Z, Zhu Y, Wang M, Wu Y, Cao J, Li C, et al. The utilization of retinal nerve fiber layer thickness to predict cognitive deterioration. J Alzheimers Dis. $2015 ; 49: 399-405$.

39. Shi Z, Zheng H, Hu J, Jiang L, Cao X, Chen Y, et al. Retinal nerve fiber layer thinning is associated with brain atrophy: a longitudinal study in nondemented older adults. Front Aging Neurosci. 2019. https://doi.org/10.3389/fnagi.2019.00069.

40. Bambo MP, Garcia-Martin E, Pinilla J, Herrero R, Satue $\mathrm{M}$, Otin $\mathrm{S}$, et al. Detection of retinal nerve fiber layer degeneration in patients with Alzheimer's disease using optical coherence tomography: searching new biomarkers. Acta Ophthalmol (Copenh). 2014;92:e581-2.

41. Trebbastoni A, D'Antonio F, Bruscolini A, Marcelli M, Cecere M, Campanelli A, et al. Retinal nerve fibre layer thickness changes in Alzheimer's disease: results from a 12-month prospective case series. Neurosci Lett. 2016;629:165-70.

42. Iseri PK, Altinas O, Tokay T, Yuksel N. Relationship between cognitive impairment and retinal morphological and visual functional abnormalities in Alzheimer disease. J Neuroophthalmol. 2006;26: 18-24.

43. Cheung CY, Ong YT, Hilal S, Ikram MK, Low S, Ong $\mathrm{YL}$, et al. Retinal ganglion cell analysis using highdefinition optical coherence tomography in patients with mild cognitive impairment and Alzheimer's disease. J Alzheimers Dis. 2015;45:45-56.

44. Kesler A, Vakhapova V, Korczyn AD, Naftaliev E, Neudorfer M. Retinal thickness in patients with mild cognitive impairment and Alzheimer's disease. Clin Neurol Neurosurg. 2011;113:523-6.

45. Garcia-Martin E, Bambo MP, Marques ML, Satue M, Otin S, Larrosa JM, et al. Ganglion cell layer measurements correlate with disease severity in patients with Alzheimer's disease. Acta Ophthalmol (Copenh). 2016;94:e454-9.

46. Gao L, Liu Y, Li X, Bai Q, Liu P. Abnormal retinal nerve fiber layer thickness and macula lutea in patients with mild cognitive impairment and Alzheimer's disease. Arch Gerontol Geriatr. 2015;60: 162-7.

47. Moschos MM, Markopoulos I, Chatziralli I, Rouvas A, Papageorgiou SG, Ladas I, et al. Structural and functional impairment of the retina and optic nerve in Alzheimer's disease. Curr Alzheimer Res. 2012;9: 782-8.

48. Lu Y, Li Z, Zhang X, Ming B, Jia J, Wang R, et al. Retinal nerve fiber layer structure abnormalities in early Alzheimer's disease: evidence in optical coherence tomography. Neurosci Lett. 2010;480: 69-72.

49. Liu D, Zhang L, Li Z, Zhang X, Wu Y, Yang H, et al. Thinner changes of the retinal nerve fiber layer in patients with mild cognitive impairment and Alzheimer's disease. BMC Neurol [Internet]. 2015. https://doi.org/10.1186/s12883-015-0268-6.

50. Berisha F, Feke GT, Trempe CL, McMeel JW, Schepens CL. Retinal abnormalities in early Alzheimer's disease. Investig Opthalmology Vis Sci. 2007; 48:2285.

51. Cunha JP, Proença R, Dias-Santos A, Almeida R, Águas $\mathrm{H}$, Alves $\mathrm{M}$, et al. OCT in Alzheimer's disease: thinning of the RNFL and superior hemiretina. Graefes Arch Clin Exp Ophthalmol. 2017;255:1827-35.

52. La Morgia C, Ross-Cisneros FN, Koronyo Y, Hannibal J, Gallassi R, Cantalupo G, et al. Melanopsin retinal ganglion cell loss in Alzheimer disease. Ann Neurol. 2015;79:90-109.

53. Kwon JY, Yang JH, Han JS, Kim DG. Analysis of the retinal nerve fiber layer thickness in Alzheimer disease and mild cognitive impairment. Korean J Ophthalmol. 2017;31:548.

54. Kirbas S, Turkyilmaz K, Anlar O, Tufekci A, Durmus M. Retinal nerve fiber layer thickness in patients with Alzheimer disease. J Neuro-Ophthalmol. 2013;33:58-61.

55. Eraslan M, Cerman E, Cekic O, Balci S, Dericioglu V, Sahin $\mathrm{O}$, et al. Neurodegeneration in ocular and central nervous systems: optical coherence tomography study in normal-tension glaucoma and Alzheimer disease. Turk J Med Sci. 2015;45:1106-14.

56. Chi Y, Wang Y, Yang L. The investigation of retinal nerve fiber loss in Alzheimer's disease. Zhonghua Yan Ke Za Zhi Chin J Ophthalmol. 2010;46:134-9. 
57. Curcio CA, Allen KA. Topography of ganglion cells in human retina. J Comp Neurol. 1990;300:5-25.

58. Blanks JC, Torigoe Y, Hinton DR, Blanks RHI. Retinal pathology in Alzheimer's disease. I. Ganglion cell loss in foveal/parafoveal retina. Neurobiol Aging. 1996;17:377-84.

59. Marziani E, Pomati S, Ramolfo P, Cigada M, Giani A, Mariani $C$, et al. Evaluation of retinal nerve fiber layer and ganglion cell layer thickness in Alzheimer's disease using spectral-domain optical coherence tomography. Invest Ophthalmol Vis Sci. 2013;54:5953-8.

60. den Haan J, Janssen SF, van de Kreeke JA, Scheltens P, Verbraak FD, Bouwman FH. Retinal thickness correlates with parietal cortical atrophy in earlyonset Alzheimer's disease and controls. Alzheimers Dement Diagn Assess Dis Monit. 2018;10:49-55.

61. Feke GT, Hyman BT, Stern RA, Pasquale LR. Retinal blood flow in mild cognitive impairment and Alzheimer's disease. Alzheimers Dement Diagn Assess Dis Monit. 2015;1:144-51.

62. Pillai JA, Bermel R, Bonner-Jackson A, Rae-Grant A, Fernandez H, Bena J, et al. Retinal nerve fiber layer thinning in Alzheimer's disease. Am J Alzheimers Dis Dementiasr. 2016;31:430-6.

63. Gharbiya M, Trebbastoni A, Parisi F, Manganiello S, Cruciani F, D'Antonio F, et al. Choroidal thinning as a new finding in Alzheimer's disease: evidence from enhanced depth imaging spectral domain optical coherence tomography. J Alzheimers Dis. 2014;40:907-17.

64. Salobrar-Garcia E, Hoyas I, Leal M, de Hoz R, Rojas $\mathrm{B}$, Ramirez AI, et al. Analysis of retinal peripapillary segmentation in Early Alzheimer's disease patients. Biomed Res Int. 2015;2015:8.

65. Sanchez D, Castilla-Marti M, Rodriguez-Gomez O, Valero S, Piferrer A, Martinez G, et al. Usefulness of peripapillary nerve fiber layer thickness assessed by optical coherence tomography as a biomarker for Alzheimer's disease. Sci Rep. 2018;8:16345.

66. Lad EM, Mukherjee D, Stinnett SS, Cousins SW, Potter GG, Burke JR, et al. Evaluation of inner retinal layers as biomarkers in mild cognitive impairment to moderate Alzheimer's disease. PLoS One. 2018;13:e0192646.

67. Forte R, Cennamo GL, Finelli ML, de Crecchio G. Comparison of time domain Stratus OCT and spectral domain SLO/OCT for assessment of macular thickness and volume. Eye. 2009;23:2071-8.

68. Zabel P, Kałużny JJ, Wiłkość-Dębczyńska M, GębskaTołoczko M, Suwała K, Kucharski R, et al.
Peripapillary retinal nerve fiber layer thickness in patients with Alzheimer's disease: a comparison of eyes of patients with Alzheimer's disease, primary open-angle glaucoma, and preperimetric glaucoma and healthy controls. Med Sci Monit. 2019;25: 1001-8.

69. Reitz C, Brayne C, Mayeux R. Epidemiology of Alzheimer disease. Nat Rev Neurol. 2011;7:137-52.

70. Cacabelos R, Fernandez-Novoa L, Lombardi V, Corzo L, Pichel V, Kubota Y. Cerebrovascular risk factors in Alzheimer's disease: brain hemodynamics and pharmacogenomic implications. Neurol Res. 2003;25:567-80.

71. Sabayan B, Jansen S, Oleksik AM, van Osch MJP, van Buchem MA, van Vliet $\mathrm{P}$, et al. Cerebrovascular hemodynamics in Alzheimer's disease and vascular dementia: a meta-analysis of transcranial Doppler studies. Ageing Res Rev. 2012;11:271-7.

72. Patton N, Aslam T, MacGillivray T, Pattie A, Deary IJ, Dhillon B. Retinal vascular image analysis as a potential screening tool for cerebrovascular disease: a rationale based on homology between cerebral and retinal microvasculatures. J Anat. 2005;206: 319-48.

73. Pérez MA, Bruce BB, Newman NJ, Biousse V. The use of retinal photography in nonophthalmic settings and its potential for neurology. Neurologist. 2012;18:350-5.

74. Cheung CY, Tay WT, Mitchell P, Wang JJ, Hsu W, Lee ML, et al. Quantitative and qualitative retinal microvascular characteristics and blood pressure. J Hypertens [Internet]. 2011;29. https://journals. lww.com/jhypertension/Fulltext/2011/07000/ Quantitative_and_qualitative_retinal_ microvascular.20.aspx.

75. Baker ML, Marino Larsen EK, Kuller LH, Klein R, Klein BE, Siscovick DS, et al. Retinal microvascular signs, cognitive function, and dementia in older persons. Stroke. 2007;38:2041-7.

76. de Jong FJ, Schrijvers EMC, Ikram MK, Koudstaal PJ, de Jong PTVM, Hofman A, et al. Retinal vascular caliber and risk of dementia: the Rotterdam study. Neurology. 2011;76:816-21.

77. Shaun F, Alauddin B, David O, James DD, Lance Macaulay S, Hamid RS, et al. Modulation of retinal arteriolar central reflection by APOE genotype. Curr Alzheimer Res. 2017;14:916-23.

78. Jung N-Y, Han JC, Ong YT, Cheung CY, Chen CP, Wong TY, et al. Retinal microvasculature changes in amyloid-negative subcortical vascular cognitive impairment compared to amyloid-positive Alzheimer's disease. J Neurol Sci. 2019;396:94-101. 
79. Provenzano FA, Muraskin J, Tosto G, Narkhede A, Wasserman BT, Griffith EY, et al. White matter hyperintensities and cerebral amyloidosis: necessary and sufficient for clinical expression of Alzheimer disease? JAMA Neurol. 2013;70:455-61.

80. Martin Dichgans, Didier Leys. Vascular cognitive impairment. Circ Res. 2017;120:573-91.

81. McGrory S, Cameron JR, Pellegrini E, Warren C, Doubal FN, Deary IJ, et al. The application of retinal fundus camera imaging in dementia: a systematic review. Alzheimers Dement Diagn Assess Dis Monit. 2017;6:91-107.

82. Cheung CY, Ong YT, Ikram MK, Ong SY, Li X, Hilal $S$, et al. Microvascular network alterations in the retina of patients with Alzheimer's disease. Alzheimers Dement. 2014;10:135-42.

83. Williams MA, McGowan AJ, Cardwell CR, Cheung CY, Craig D, Passmore P, et al. Retinal microvascular network attenuation in Alzheimer's disease. Alzheimers Dement Diagn Assess Dis Monit. 2015;1: 229-35.

84. Campbell JP, Zhang M, Hwang TS, Bailey ST, Wilson DJ, Jia Y, et al. Detailed vascular anatomy of the human retina by projection-resolved optical coherence tomography angiography. Sci Rep. 2017;7: 42201.

85. Spaide RF, Klancnik JM Jr, Cooney MJ. Retinal vascular layers imaged by fluorescein angiography and optical coherence tomography angiography. JAMA Ophthalmol. 2015;133:45-50.

86. Koustenis AJ, Harris A, Gross J, Januleviciene I, Shah A, Siesky B. Optical coherence tomography angiography: an overview of the technology and an assessment of applications for clinical research. Br J Ophthalmol. 2017;101:16-20.

87. Lahme L, Esser EL, Mihailovic N, Schubert F, Lauermann J, Johnen A, et al. Evaluation of ocular perfusion in Alzheimer's disease using optical coherence tomography angiography. J Alzheimers Dis. 2018;66:1745-52.

88. Jiang H, Wei Y, Shi Y, Wright CB, Sun X, Gregori G, et al. Altered macular microvasculature in mild cognitive impairment and Alzheimer disease. J Neuro-Ophthalmol. 2018;38:292-8.

89. Grewal DS, Polascik BW, Hoffmeyer GC, Fekrat S. Assessment of differences in retinal microvasculature using OCT angiography in Alzheimer's disease: a twin discordance report. Ophthalmic Surg Lasers Imaging Retina. 2018;49:440-4.

90. Bulut M, Kurtuluş F, Gözkaya O, Erol MK, Cengiz A, Akıdan M, et al. Evaluation of optical coherence tomography angiographic findings in Alzheimer's type dementia. Br J Ophthalmol. 2017;102:233-7.

91. Zhang YS, Zhou N, Knoll BM, Samra S, Ward MR, Weintraub S, et al. Parafoveal vessel loss and correlation between peripapillary vessel density and cognitive performance in amnestic mild cognitive impairment and early Alzheimer's Disease on optical coherence tomography angiography. PLoS One. 2019;14:e0214685.

92. Nielsen RB, Egefjord L, Angleys H, Mouridsen K, Gejl M, Møller A, et al. Capillary dysfunction is associated with symptom severity and neurodegeneration in Alzheimer's disease. Alzheimers Dement. 2017;13:1143-53.

93. Querques G, Borrelli E, Sacconi R, De Vitis L, Leocani L, Santangelo R, et al. Functional and morphological changes of the retinal vessels in Alzheimer's disease and mild cognitive impairment. Sci Rep [Internet]. 2019. https://doi.org/10.1038/ s41598-018-37271-6.

94. Chui TYP, Zhong Z, Song H, Burns SA. Foveal avascular zone and its relationship to foveal pit shape. Optom Vis Sci. 2012;89:602-10.

95. Bresnick GH, Condit R, Syrjala S, Palta M, Groo A, Korth K. Abnormalities of the foveal avascular zone in diabetic retinopathy. JAMA Ophthalmol. 1984;102:1286-93.

96. O’Bryhim BE, Apte RS, Kung N, Coble D, Van Stavern GP. Association of preclinical Alzheimer disease with optical coherence tomographic angiography findings. JAMA Ophthalmol. 2018;136:1242.

97. van de Kreeke JA, Nguyen H-T, Konijnenberg E, Tomassen J, den Braber A, ten Kate M, et al. Optical coherence tomography angiography in preclinical Alzheimer's disease. Br J Ophthalmol. 2019;bjophthalmol-2019-314127.

98. Bhat AH, Dar KB, Anees S, Zargar MA, Masood A, Sofi MA, et al. Oxidative stress, mitochondrial dysfunction and neurodegenerative diseases; a mechanistic insight. Biomed Pharmacother. 2015;74: 101-10.

99. Stefánsson E, Olafsdottir OB, Eliasdottir TS, Vehmeijer W, Einarsdottir AB, Bek T, et al. Retinal oximetry: metabolic imaging for diseases of the retina and brain. Prog Retin Eye Res. 2019;70:1-22.

100. Hardarson SH. Retinal oximetry. Acta Ophthalmol (Copenh). 2013;91:1-47.

101. Einarsdottir AB, Hardarson SH, Kristjansdottir JV, Bragason DT, Snaedal J, Stefánsson E. Retinal 
oximetry imaging in Alzheimer's disease. J Alzheimers Dis. 2015;49:79-83.

102. Olafsdottir OB, Saevarsdottir HS, Hardarson SH, Hannesdottir KH, Traustadottir VD, Karlsson RA, et al. Retinal oxygen metabolism in patients with mild cognitive impairment. Alzheimers Dement Diagn Assess Dis Monit. 2018;10:340-5.

103. Hollo G. Optical coherence tomography angiography in glaucoma. Turk J Ophthalmol. 2018;48: 196-201.

104. Werner AC, Shen LQ. A review of OCT angiography in glaucoma. Semin Ophthalmol. 2019;34:279-86.

105. Mwanza J-C, Chang RT, Budenz DL, Durbin MK, Gendy MG, Shi W, et al. Reproducibility of peripapillary retinal nerve fiber layer thickness and optic nerve head parameters measured with cirrus HD-OCT in glaucomatous eyes. Invest Ophthalmol Vis Sci. 2010;51:5724-30.

106. Fritsche LG, Fariss RN, Stambolian D, Abecasis GR, Curcio CA, Swaroop A. Age-related macular degeneration: genetics and biology coming together. Annu Rev Genomics Hum Genet. 2014;15:151-71.

107. Csincsik L, MacGillivray TJ, Flynn E, Pellegrini E, Papanastasiou G, Barzegar-Befroei N, et al. Peripheral retinal imaging biomarkers for Alzheimer's disease: a pilot study. Ophthalmic Res. 2018;59: 182-92.

108. Anderson DH, Talaga KC, Rivest AJ, Barron E, Hageman GS, Johnson LV. Characterization of $\beta$ amyloid assemblies in drusen: the deposits associated with aging and age-related macular degeneration. Exp Eye Res. 2004;78:243-56.

109. Dentchev T, Milam AH, Lee VMY, Trojanowski JQ, Dunaief JL. Amyloid- $\beta$ is found in drusen from some age-related macular degeneration retinas, but not in drusen from normal retinas. In: Hans $\mathrm{E}$, Grossniklaus MD (eds) Am J Ophthalmol. 2003;136:787.

110. Johnson LV, Leitner WP, Rivest AJ, Staples MK, Radeke MJ, Anderson DH. The Alzheimer's A betapeptide is deposited at sites of complement activation in pathologic deposits associated with aging and age-related macular degeneration. Proc Natl Acad Sci USA. 2002;99:11830-5.

111. Brandl C, Brücklmayer C, Günther F, Zimmermann ME, Küchenhoff $\mathrm{H}$, Helbig $\mathrm{H}$, et al. Retinal layer thicknesses in early age-related macular degeneration: results from the german AugUR study. Invest Ophthalmol Vis Sci. 2019;60:1581-94.

112. Schuman SG, Koreishi AF, Farsiu S, Jung S, Izatt JA, Toth CA. Photoreceptor layer thinning over drusen in eyes with age-related macular degeneration imaged in vivo with spectral-domain optical coherence tomography. Ophthalmology. 2009;116(488-496):e2.

113. Sadigh S, Cideciyan AV, Sumaroka A, Huang WC, Luo X, Swider M, et al. Abnormal thickening as well as thinning of the photoreceptor layer in intermediate age-related macular degeneration. Invest Ophthalmol Vis Sci. 2013;54:1603-12.

114. Uchida A, Pillai JA, Bermel R, Bonner-Jackson A, Rae-Grant A, Fernandez $H$, et al. Outer retinal assessment using spectral-domain optical coherence tomography in patients with Alzheimer's and Parkinson's disease. Invest Ophthalmol Vis Sci. 2018;59:2768-77.

115. Mancino R, Martucci A, Cesareo M, Giannini C, Corasaniti MT, Bagetta G, et al. Glaucoma and Alzheimer disease: one age-related neurodegenerative disease of the brain. Curr Neuropharmacol. 2018;16:971-7.

116. McKinnon SJ, Lehman DM, Kerrigan-Baumrind LA, Merges CA, Pease ME, Kerrigan DF, et al. Caspase activation and amyloid precursor protein cleavage in rat ocular hypertension. Invest Ophthalmol Vis Sci. 2002;43:1077-87.

117. Guo L, Salt TE, Luong V, Wood N, Cheung W, Maass A, et al. Targeting amyloid-beta in glaucoma treatment. Proc Natl Acad Sci USA. 2007;104: 13444-9.

118. Gupta N, Fong J, Ang LC, Yücel YH. Retinal tau pathology in human glaucomas. Can J Ophthalmol. 2008;43:53-60.

119. Yoneda S, Hara H, Hirata A, Fukushima M, Inomata Y, Tanihara H. Vitreous fluid levels of beta-amyloid (1-42) and tau in patients with retinal diseases. Jpn J Ophthalmol. 2005;49:106-8.

120. Cesareo M, Martucci A, Ciuffoletti E, Mancino R, Cerulli A, Sorge RP, et al. Association between Alzheimer's disease and glaucoma: a study based on Heidelberg retinal tomography and frequency doubling technology perimetry. Front Neurosci. 2015;9: 479.

121. Yang F, Lim GP, Begum AN, Ubeda OJ, Simmons MR, Ambegaokar SS, et al. Curcumin inhibits formation of amyloid $\beta$ oligomers and fibrils, binds plaques, and reduces amyloidin vivo. J Biol Chem. 2004;280:5892-901.

122. Koronyo Y, Biggs D, Barron E, Boyer DS, Pearlman JA, Au WJ, et al. Retinal amyloid pathology and proof-of-concept imaging trial in Alzheimer's disease. JCI Insight [Internet]. 2017. https://doi.org/10. 1172/jci.insight.93621. 
123. Williams EA, McGuone D, Frosch MP, Hyman BT, Laver N, Stemmer-Rachamimov A. Absence of Alzheimer disease neuropathologic changes in eyes of subjects with Alzheimer disease. J Neuropathol Exp Neurol. 2017;76:376-83.

124. Schön C, Hoffmann NA, Ochs SM, Burgold S, Filser $S$, Steinbach S, et al. Long-term in vivo imaging of fibrillar tau in the retina of P301S transgenic mice. PLoS One. 2012;7:e53547.

125. Ho C-Y, Troncoso JC, Knox D, Stark W, Eberhart CG. Beta-amyloid, phospho-tau and alpha-synuclein deposits similar to those in the brain are not identified in the eyes of Alzheimer's and Parkinson's disease patients. Brain Pathol. 2013;24:25-32.

126. Hinton DR, Sadun AA, Blanks JC, Miller CA. Opticnerve degeneration in Alzheimer's disease. N Engl J Med. 1986;315:485-7.

127. Leger F, Fernagut P-O, Canron M-H, Léoni S, Vital $\mathrm{C}$, Tison $\mathrm{F}$, et al. Protein aggregation in the aging retina. J Neuropathol Exp Neurol. 2011;70:63-8.

128. Jiang J, Wang H, Li W, Cao X, Li C. Amyloid plaques in retina for diagnosis in Alzheimer's patients: a meta-analysis. Front Aging Neurosci [Internet]. 2016. https://doi.org/10.3389/fnagi.2016.00267.

129. Ong SS, Doraiswamy PM, Lad EM. Controversies and future directions of ocular biomarkers in Alzheimer disease. JAMA Neurol. 2018;75:650.

130. Morris M, Maeda S, Vossel K, Mucke L. The many faces of tau. Neuron. 2011;70:410-26.

131. den Haan J, Morrema THJ, Verbraak FD, de Boer JF, Scheltens P, Rozemuller AJ, et al. Amyloid-beta and phosphorylated tau in post-mortem Alzheimer's disease retinas. Acta Neuropathol Commun. 2018. https://doi.org/10.1186/s40478-018-0650-x.

132. Sadda SR, Borrelli E, Fan W, Ebraheem A, Marion $\mathrm{KM}$, Harrington $\mathrm{M}$, et al. A pilot study of fluorescence lifetime imaging ophthalmoscopy in preclinical Alzheimer's disease. Eye Lond Engl. 2019;33:1271-9.

133. Jentsch S, Schweitzer D, Schmidtke K-U, Peters S, Dawczynski J, Bar K-J, et al. Retinal fluorescence lifetime imaging ophthalmoscopy measures depend on the severity of Alzheimer's disease. Acta Ophthalmol (Copenh). 2015;93:e241-7.

134. Alamouti B, Funk J. Retinal thickness decreases with age: an OCT study. Br J Ophthalmol. 2003;87: 899-901.

135. Wei Y, Jiang H, Shi Y, Qu D, Gregori G, Zheng F, et al. Age-related alterations in the retinal microvasculature, microcirculation, and microstructure. Invest Ophthalmol Vis Sci. 2017;58: 3804-17.

136. Lin Y, Jiang H, Liu Y, Rosa Gameiro G, Gregori G, Dong $\mathrm{C}$, et al. Age-related alterations in retinal tissue perfusion and volumetric vessel density. Invest Ophthalmol Vis Sci. 2019;60:685-93.

137. Iafe NA, Phasukkijwatana N, Chen X, Sarraf D. Retinal capillary density and foveal avascular zone area are age-dependent: quantitative analysis using optical coherence tomography angiography. Invest Ophthalmol Vis Sci. 2016;57:5780-7.

138. Ooto S, Vongkulsiri S, Sato T, Suzuki M, Curcio CA, Spaide RF. Outer retinal corrugations in age-related macular degeneration. JAMA Ophthalmol. 2014;132:806-13.

139. Karampelas M, Sim DA, Keane PA, Papastefanou VP, Sadda SR, Tufail A, et al. Evaluation of retinal pigment epithelium-Bruch's membrane complex thickness in dry age-related macular degeneration using optical coherence tomography. Br J Ophthalmol. 2013;97:1256.

140. Santos CY, Johnson LN, Sinoff SE, Festa EK, Heindel WC, Snyder PJ. Change in retinal structural anatomy during the preclinical stage of Alzheimer's disease. Alzheimers Dement Diagn Assess Dis Monit. 2018;10:196-209.

141. den Haan J, van de Kreeke JA, van Berckel BN, Barkhof F, Teunissen CE, Scheltens P, et al. Is retinal vasculature a biomarker in amyloid proven Alzheimer's disease? Alzheimers Dement Diagn Assess Dis Monit. 2019;11:383-91.

142. Frost S, Kanagasingam Y, Sohrabi H, Vignarajan J, Bourgeat $\mathrm{P}$, Salvado $\mathrm{O}$, et al. Retinal vascular biomarkers for early detection and monitoring of Alzheimer's disease. Transl Psychiatry. 2013;3:e233.

143. Sousa DC, Leal I, Moreira S, Dionísio P, Abegão Pinto L, Marques-Neves C. Hypoxia challenge test and retinal circulation changes-a study using ocular coherence tomography angiography. Acta Ophthalmol (Copenh). 2018;96:e315-9.

144. Marchesi VT. Alzheimer's dementia begins as a disease of small blood vessels, damaged by oxidative-induced inflammation and dysregulated amyloid metabolism: implications for early detection and therapy. FASEB J. 2011;25:5-13.

145. Grimaldi A, Brighi C, Peruzzi G, Ragozzino D, Bonanni V, Limatola $\mathrm{C}$, et al. Inflammation, neurodegeneration and protein aggregation in the retina as ocular biomarkers for Alzheimer's disease in the 3xTg-AD mouse model. Cell Death Dis. 2018;9:685. 
146. Knoll B, Simonett J, Volpe NJ, Farsiu S, Ward M, Rademaker A, et al. Retinal nerve fiber layer thickness in amnestic mild cognitive impairment: case- control study and meta-analysis. Alzheimers Dement Amst Neth. 2016;4:85-93. 